\title{
RHEOLOGICAL CONTROL OF WADATI-BENIOFF ZONE SEISMICITY
}

\author{
John Brodholt and Seth Stein
}

Department of Geological Sciences, Northwestern University

\begin{abstract}
Intermediate and deep focus earthquakes in Wadati-Benioff zones are thought to occur in the cold interiors of downgoing slabs which are significantly stronger than the warmer mantle. Given that earthquakes in oceanic lithosphere appear restricted by an isotherm, and hence a given value of lithospheric strength, we investigate whether a similar formulation is useful for subducting plates. Strength in downgoing slabs should be affected by both pressure and temperature, an effect previously treated using a depth-dependent limiting temperature for seismicity [Wortel, 1982]. We find this limiting temperature implies that a possible limiting strength increases strongly with depth, unless either the temperatures were too low or the activation volume too large. Comparison of the analytic model used by Wortel with numerical thermal models appears to exclude the first possibility. We explore the second possibility by using the numerical thermal model to compute strength contours for flow law constants reported from laboratory experiments, and find that the expected pressure strengthening is large enough that the slab should have considerable strength well below the deepest seismicity. We conclude that if laboratory results are applicable to these conditions, either a strongly depth-dependent limiting strength exists or factors in addition to strength control the distribution of subduction zone earthquakes.
\end{abstract}

\section{Introduction}

Subduction zone earthquakes occur to depths of $700 \mathrm{~km}$; elsewhere, earthquakes deeper than tens of $\mathrm{km}$ are rare. Sleep [1973] comparing epicenter locations in the Aleutians to a modeled thermal structure, noted that seismicity was restricted to the cold interior of the slab. Figure 1 illustrates this using well located earthquakes [Engdahl and Gubbins, 1987] and a numerical thermal model. Almost all earthquakes fall within the $1000^{\circ} \mathrm{C}$ isotherm. Several points in such analyses are worth noting. To obtain an adequate sample, earthquakes over $-500 \mathrm{~km}$ were summed and compared to a single thermal model, an approximation since the obliquity of subduction varies along the arc. Moreover, earthquakes are positioned somewhat subjectively with respect to the temperature profile. Nonetheless, despite these simplifications and the difficulty that slabs are identified largely from seismicity, it is generally assumed that earthquakes occur in their cold interiors. This is consistent with observations [Sleep, 1973; Jordan, 1977; Fujita et al., 1981; Creager and Jordan, 1984; 1986] that slabs delineated by seismicity provide fast seismic wave paths.

If the seismicity distribution reflects temperature structure, it provides at least a qualitative constraint on the

Copyright 1988 by the American Geophysical Union.

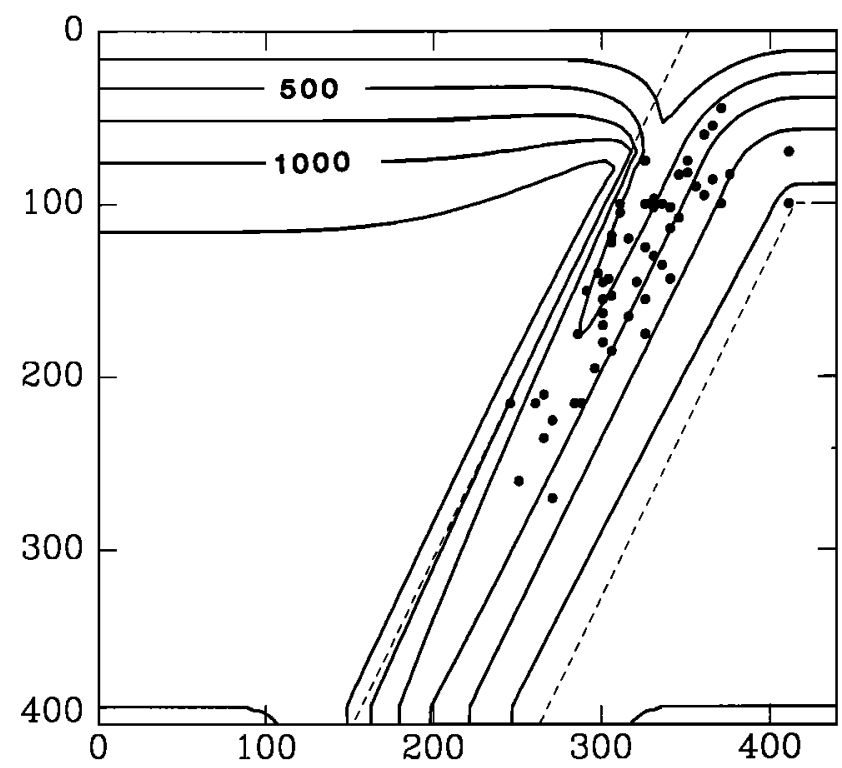

Fig. 1. Seismicity and thermal structure for the Aleutians. Most earthquakes occur in the cold interior of the slab, within the $1000^{\circ} \mathrm{C}$ isotherm.

rheology of downgoing slabs. Also, since the maximum depth of seismicity varies between subduction zones, it offers a test for subduction thermal models. Such models [McKenzie, 1969; 1970] predict that a potential temperature isotherm within the slab penetrates the mantle to a depth approximately proportional to the product of convergence rate and the age of subducting lithosphere. Data from various subduction zones show that the lengths of the Wadati-Benioff zones are also proportional to the product of convergence rate and age [Molnar et al., 1979], again suggesting that the seismicity distribution in slabs is temperature dependent. However, the seismicity locations also appear to be pressure dependent since predicted temperatures at the deepest earthquakes increase with depth (Figure 2). Wortel [1982] modeled this with a depth dependent critical temperature above which subducting lithosphere cannot support the necessary stresses for seismic failure. The critical temperature, assumed to be a fraction of the olivine melting temperature, fit the data quite well. Molnar et al. [1979] observed that the deepest earthquakes occur at an approximately constant potential temperature, the temperature expected for material moved adiabatically to a reference depth, and found the reason for this effect not obvious. Wortel's calculations explain this since the solidus in his calculations is essentially an adiabat.

An alternative is to assume that the seismicity distribution is related to lithospheric strength, the maximum differential stress sustainable. For temperatures and pressures in the subducting plate, lithosphere strength can be 


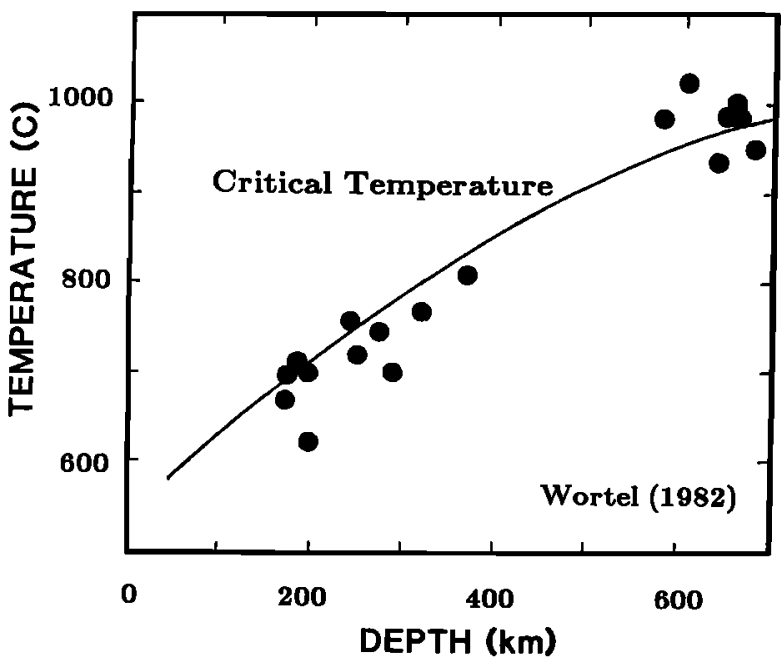

Fig. 2. Comparison of various subduction zones showing the depth of the deepest earthquakes and the temperature predicted at that depth by a thermal model. These temperatures increase with depth. The line shows a theoretically derived critical temperature, the maximum temperature at which earthquakes can occur.

approximated by a ductile flow law for olivine [Kirby, 1983; Goetze and Evans, 1979]. The strength $\sigma$ is

$$
\sigma(T, P)^{n}=\dot{e} / A \exp \left[\left(E^{*}+P V^{*}\right) / R T\right]
$$

where $\dot{e}$ is strain rate, $T$ is temperature, $P$ is pressure, and $R$ is the gas constant. The activation energy, $E^{*}$, the activation volume, $V^{*}, n$, and $A$, are estimated from laboratory studies. Lithospheric strength decreases with temperature and increases with pressure.

This formulation proved useful in describing the depth distribution of oceanic intraplate seismicity; the maximum depth of such earthquakes and hence the portion of the plate rigid enough for faulting, increases with lithospheric age [Wiens and Stein, 1983; Chen and Molnar, 1983]. This depth corresponds approximately to the predicted $750^{\circ} \mathrm{C}$ isotherm. Since the pressure variation over this shallow $(<60 \mathrm{~km})$ depth range is small, this isotherm corresponds approximately to a locus of constant lithospheric strength which must be exceeded to allow seismicity. This formulation can be used for a broad range of flow law constants, although the value of the estimated limiting strength varies. For Brace and Kohlstedt's [1980] dry olivine rheology the $750^{\circ} \mathrm{C}$ isotherm corresponds to $\sim 20 \mathrm{MPa}$ limiting strength. Thus, since subducting slabs consist of oceanic lithosphere, it is natural to ask whether a similar limiting strength concept, including strengthening by increased pressure, may be useful.

\section{Critical Temperature and Limiting Strength}

We first examined the implications of Wortel's [1982] critical temperature values for a possible limiting strength of subduction zone seismicity. His $T_{c r}(z)$ values provide a locus in temperature and depth (hence pressure) which characterize the deepest earthquakes. Thus, given a flow law, the predicted strength $\sigma\left(T_{c r}(z), P(z)\right)$ for any point along the $T_{c r}(z)$ curve in Figure 2 can be calculated. Figure 3 shows the results for $\log _{10} A=4.8 \pm 1.2 \mathrm{~s}^{-1} \mathrm{MPa}^{-n}$,

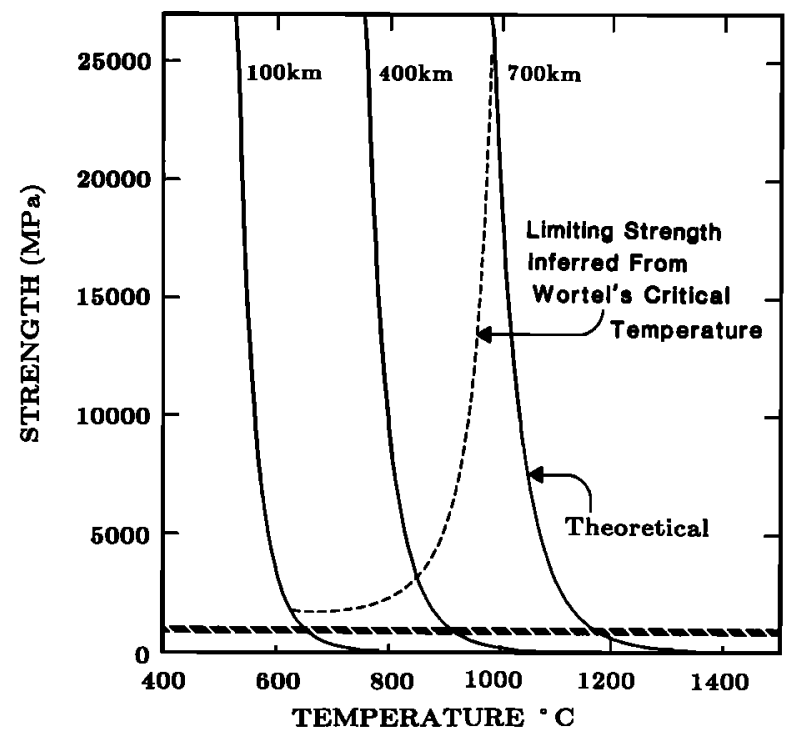

Fig. 3. Strength as a function of temperature for a dry olivine rheology. Solid lines show the dependence of strength on temperature for three representative depths using a power law rheology. Wortel's critical temperature values result in an increasing critical strength with depth (thin dashed line) rather than a constant value of critical strength (thick dashed line).

$n=3.5 \pm 0.6, \quad E^{*}=533 \pm 60 \mathrm{KJ} / \mathrm{mol}, \quad V^{*}=(17 \pm 4) \times 10^{-6}$ $\mathrm{m}^{3} / \mathrm{mol}$ [Kirby, 1983] and a strain rate of $10^{-18} \mathrm{~s}^{-1}$. Strength curves for this flow law, as functions of temperature, for pressures corresponding to various depths illustrate pressure strengthening and temperature weakening. Their intersection with a constant strength line shows how the limiting temperature would increase with depth for a pressure-independent limiting strength. In contrast, the curve for the critical temperature shows the inferred limiting strength increasing strongly with depth. It is worth noting that this strength exceeds that for which the flow law is known to be applicable [Kirby, 1983].

There is no a priori reason why, even assuming the distribution of subduction zone earthquakes were controlled by a strength criterion, that the limiting value should be constant with depth. Nonetheless, it is natural to ask whether the increase of limiting strength with depth might be only apparent. The derivation of the strength curve from the critical temperatures suggests two ways in which this might occur. First, at the depths of the deepest earthquakes, the inferred temperatures might be too low. Second, the assumed activation volume might be too high. We thus examined these possibilities, both of which result in an overestimate of strength.

Wortel [1982] calculated the temperature at the deepest earthquakes using an analytical thermal model of the subducting slab. An alternative model uses finite difference numerical solutions [Sleep, 1973; Toksoz et al., 1973] incorporating mantle flow. The success of such models in studies of travel time anomalies due to subducting slabs argues for their general validity. We compared temperatures given by the numerical model to those of Wortel. The numerical model was calculated using potential temperature and corrected for adiabatic compression [McKen- 
zie, 1969; 1970] using values of $1.12 \times 10^{7} \mathrm{erg} / \mathrm{gm}^{\circ} \mathrm{C}$ for the heat capacity and $3.0 \times 10^{-5 \circ} \mathrm{C}^{-1}$ for the coefficient of ther$\mathrm{mal}$ expansion. These satisfy the constraint that the olivine-spinel phase change occur at $-400 \mathrm{~km}$ depth and $-1500^{\circ} \mathrm{C}$ [Bina and Wood, 1986]. Below the phase boundary we simulated the latent heat by adding $135^{\circ} \mathrm{C}$. For the Aleutian slab, assuming 48 my old lithosphere subducting at $6 \mathrm{~cm} / \mathrm{yr}$ [Jarrard, 1986], the model predicts $-600^{\circ} \mathrm{C}$ in the slab at $250 \mathrm{~km}$ (Figure 1), whereas Wortel found for a somewhat different convergence rate and age, $-750^{\circ} \mathrm{C}$. Comparison of the analytical temperature model used by Wortel and the finite difference model used here for the same convergence rate and age, suggests that the lower temperatures result primarily from the fact that we use a downgoing slab of constant dip, whereas Wortel converted the downdip length of a slab to depth accounting for variable dip. Since the slab dips less steeply at shallow depths, in Wortels geometry material at a given depth follows a longer path and thus is heated for a longer time. Given that the two models predict comparable temperatures, we consider it unlikely that the apparent high strengths result from a too-cold temperature model.

We also investigated whether a lower activation volume would allow seismicity to be limited by a depthindependent strength. We plotted strength contours for subducting slabs on thermal profiles from the finite difference model. Figures 4 and 5 show representative strength contours for strain rates encompassing estimates of the seismic strain rate [Kawakatsu, 1986]. Figure 4 is calculated for $94 \mathrm{my}$ lithosphere subducting at $9.9 \mathrm{~cm} / \mathrm{yr}$, values comparable to N. E. Japan [Jarrard, 1986] where seismicity occurs to $600 \mathrm{~km}$. For (top panels) the average flow law constants from laboratory experiments [Kirby, 1983], the strength contours do not close about the deepest seismicity, as required for a constant limiting strength. The pressure strengthening is large enough that the slab would
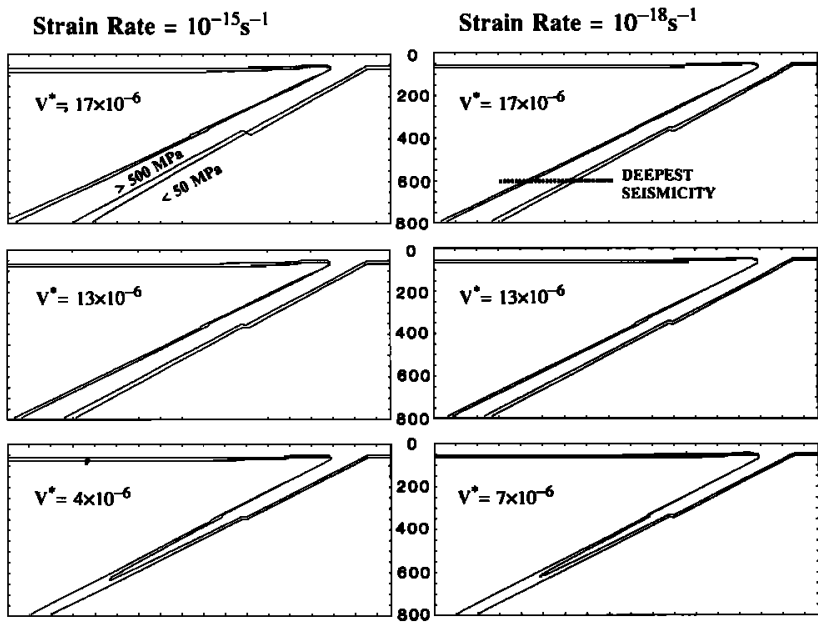

Fig. 4. Strength contours for a thermal model comparable to the N. E. Japan subduction zone and a power law rheology, for two representative strain rates. For the expected flow law values, (top and center panels), the slab is strong to depths well below the deepest earthquakes. Only for very low activation volumes, $V^{*}\left(\mathrm{~m}^{3} \mathrm{~mole}^{-1}\right)$, does the slab become weak at the depths of the deepest earthquakes (bottom panels).
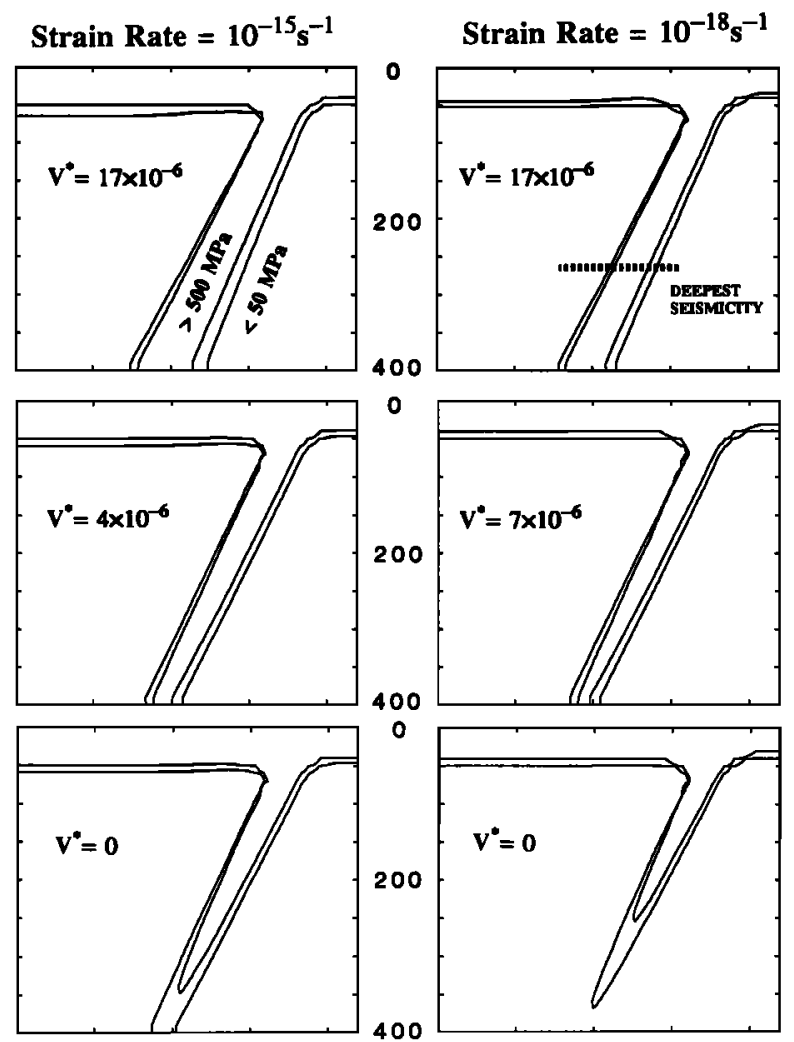

Fig. 5. Strength contours for a thermal model comparable to the Aleutian subduction zone. Only for a zero activation volume (bottom panels) does the slab become weak at the depths of the deepest earthquakes.

have considerable strength well below the deepest seismicity and the strong region actually widens with depth. Even for the lower limit of the activation volume range (center panels), the strength contours do not enclose the deepest earthquakes. Only for significantly lower $V^{*}$ values (lower panels), is pressure strengthening small enough that seismicity can be limited by a single strength.

However, for a different subduction zone even this low activation volume is inadequate. Figure 5 shows younger (48 my) lithosphere subducting at a slower velocity, 6 $\mathrm{cm} / \mathrm{yr}$. Values approximate the Aleutians where seismicity extends to about $300 \mathrm{~km}$. The short slab indicated by the seismicity should not result from recent initiation of subduction; convergence has occurred for about $60 \mathrm{my}$ [Jarrard, 1986]. As for the previous case, for the average value of the activation volume a constant limiting strength predicts seismicity deeper than observed. Moreover, the activation volume values that bounded the $\mathrm{N}$. E. Japan seismicity are unable to do so here. Only for $\left(V^{*}=0\right)$ does a uniform strength begin to bound seismicity. In this extreme case, isotherms are curves of constant strength.

The same difficulties occur for the range of values of the other flow law constants. The pressure strengthening effect is large enough that a constant limiting strength does not bound the observed seismicity.

\section{Discussion}

These results imply that although seismicity in downgoing slabs is restricted to their cold and strong interior, the 
seismicity distribution is not easily described as controlled by a single lithospheric strength value. Three general possibilities emerge. Perhaps the limiting strength idea is valid, but the laboratory results used here are inapplicable to conditions in a subducting slab. For example, the same flow law constants were used as a function of depth, even below the olivine-spinel phase change. Similarly, the activation energy may be lower than the value used, possibly due to the presence of water [Kirby, 1983], such that the slab would be weaker as suggested from calculations of the stresses in double seismic zones [Kawakatsu, 1986]. This possibility reflects the long recognized difficulty that the strength, and hence stresses, at the depths of intermediate and deep focus earthquakes are extremely high and that such seismicity may be due to quite different processes than in the lithosphere [Kirby ,1987].

If, on the other hand, laboratory results are applicable, then any limiting strength must be strongly depth dependent. This idea has the unattractive circular feature that the limiting strength would be inferred from seismicity. Alternatively, the earthquake locations may be governed by factors in addition to strength. Wortel [1986] suggests that regions of downgoing slabs, though strong enough to permit earthquakes, are aseismic due to the stress distribution.

A limiting strength for seismicity would have interesting implications for the question of whether the restriction of seismicity to depths shallower than the $670 \mathrm{~km}$ discontinuity requires that slabs not extend below this depth, or indicates merely that deeper portions are aseismic [Jordan, 1977; Hager and O'Connell, 1978; Richter, 1979; Creager and Jordan, 1986; Wortel, 1986]. In particular, were seismicity rheologically controlled, such that it ceases in the deepest slabs for the same reason that it stops at shallower depths in other slabs, the depth of earthquakes would not preclude slabs penetrating below $670 \mathrm{~km}$. Since we find no clear case for purely rheological control, our results do not directly discriminate between models.

Acknowledgements. We thank Norman Sleep for providing his subduction zone temperature model program. We also thank Rinus Wortel and two anonymous reviewers for helpful comments. This research was supported by NSF grants EAR 8618038 and INT 8610654, NASA grant NAG 5-885 and NATO grant 0148/87.

\section{References}

Bina, C. R., and B. J. Wood, The $400 \mathrm{~km}$ seismic discontinuity and the proportion of olivine in the Earth's upper mantle, Nature, 324, 449-451, 1986.

Brace, W. F., and D. L. Kohlstedt, Limits on lithospheric stress imposed by laboratory experiments, $J$. Geophys. Res., 85, 6248-6252, 1980.

Chen, W.-P., and P. Molnar, Focal depths of intracontinental and intraplate earthquakes and their implications for the thermal and mechanical properties of the lithosphere, J. Geophys. Res., 88, 4183-4214, 1983.

Creager, K. C., and T. H. Jordan, Slab penetration into the lower mantle, J. Geophys. Res., 89, 3031-3049, 1984.

Creager, K. C., and T. H. Jordan, Slab penetration into the lower mantle beneath the Mariana and other island arcs of the northwest Pacific, J. Geophys. Res., 91, 3573$3589,1986$.

Engdahl, E. R., and D. A. Gubbins, Simultaneous travel time inversion for earthquake location and subduction zone structure in the central Aleutians, J. Geophys. Res., 92, 13855-13862, 1987.

Fujita, K., E. R. Engdahl, and N. H. Sleep, Subduction zone calibration and teleseismic relocation of thrust zone events in the central Aleutian Islands, Bull. Seismol. Soc. Am., 71, 1805-1828, 1981.

Goetze, C., and B. Evans, Stress and temperature in the bending lithosphere as constrained by experimental rock mechanics, Geophys. J., 59, 463-478, 1979.

Hager, B. H., and R. J. O'Connell, Subduction zone dip angles and flow driven by plate motion, Tectonophysics, 50, 111-133, 1978.

Jarrard, R. D., Relations among subduction parameters, Rev. Geophys., 24, 217-284, 1986.

Jordan, T. H., Lithospheric slab penetration into the lower mantle beneath the Sea of Okhotsk, J. Geophys., 43, 473-496, 1977.

Kawakatsu, H., Double seismic zones: kinematics, J. Geophys. Res., 91, 4811-4825, 1986.

Kirby, S. H., Rheology of the lithosphere, Rev. Geophys. Space Phys., 21, 1458-1487, 1983.

Kirby, S. H., Localized polymorphic phase transitions in high-pressure faults and applications to the physical mechanism of deep earthquakes, $J$. Geophys. Res., 92, 13789-13800, 1987.

McKenzie, D. P., Speculations on the consequences and causes of plate motions, Geophys. J. R. Astron. Soc., 18, 1-32, 1969.

McKenzie, D. P., Temperature and potential temperature beneath island arcs, Tectonophysics, 10, 357-366, 1970.

Molnar, P., D. Freedman, and J. S. F. Shih, Lengths of intermediate and deep seismic zones and temperatures in downgoing slabs of lithosphere, Geophys. $J$. $R$. Astron. Soc., 56, 41-54, 1979.

Richter, F. M., Focal mechanisms and seismic energy release of deep and intermediate earthquakes in the Tonga-Kermadec region and the depth extent of mantle flow, J. Geophys. Res., 84, 6783-6795, 1979.

Sleep, N. H., Teleseismic P-wave transmission through slabs, Bull. Seismol. Soc. Am., 63, 1349-1373, 1973.

Toksoz, M. N., N. H. Sleep, and A. T. Smith, Evolution of the downgoing lithosphere and mechanisms of deep focus earthquakes, Geophys. J. R. Astron. Soc., 35, 285-310, 1973.

Wiens, D. A., and S. Stein, Age dependence of oceanic intraplate seismicity and implications for lithospheric evolution, J. Geophys. Res., 88, 6455-6468, 1983.

Wortel, M. J. R., Seismicity and rheology of subducted slabs, Nature, 296, 553-556, 1982.

Wortel, M. J. R., Deep earthquakes and the thermal assimilation of subducting lithosphere, Geophys. Res. Lett., 13, 34-37, 1986.

J. Brodholt and S. Stein, Department of Geological Sciences, Northwestern University, Evanston, IL 60208.

(Received February 10, 1988; accepted March 18, 1988.) 